\title{
Of knowledge and beauty
}

\author{
In 1664, Robert Boyle wrote: "So much admirable workmanship, as God hath displayed in the Universe, \\ was never meant for eyes that willfully close themselves." It is scientists' duty to make a convincing \\ effort to ensure that this admirable workmanship is there for all to see.
}

What made Galileo point his telescope to the sky, Lavoisier develop new techniques to investigate matter, and Einstein spend sleepless nights wondering about the ultimate law of the Universe? Curiosity, yes, and a sense of beauty.

Humans are a curious bunch. Babies taste everything within their grasp, teenagers feel the compulsion to undergo experiences, and scientists want to study things for the first time. It is this feeling each one of us experiences when we are not satisfied about something - to know more, to improve, to fix - that creates new knowledge. This condition of general dissatisfaction, the result of a continual tension between our limits and our desires, acts as a powerful driving force for all that we do.

From our vantage point as human beings, limited in space, time and capabilities we can fully appreciate the imponderable beauty of the Universe. We feel its vastness can fulfil all our desires, and we are drawn in; but it's an illusion for we will never be able to comprehend what this all means. Yet, just a glimpse of that beauty is all we seek, a drop of water for thirsty lips. And hence we investigate, ask questions, strive to find things out. When Dirac, working alone in the autumn of 1927 derived the equation that bears his name, he kept silent for weeks, afraid something could happen to such a mathematical beauty. He could not face the prospect (as he recounted) that something could "just knock the whole thing on the head", as if his equation was mainly there to be admired.

Science embodies this all too human sentiment, and that is why it unites all peoples behind it and continues to inspire teenagers around the world. Science knows no geographical or historical borders. When in the Middle Ages, Arab scholars discovered the wealth of knowledge accumulated in ancient Greek, Persian and Indian texts they avidly translated them into Arabic; they recognized that knowledge is not bound to a specific culture and created one of the most majestic examples of cosmopolitan institutions purely dedicated to the pursue of knowledge: the House of Wisdom in Baghdad. Later, the Renaissance and the Scientific Revolution in Europe owed a great deal to the progresses

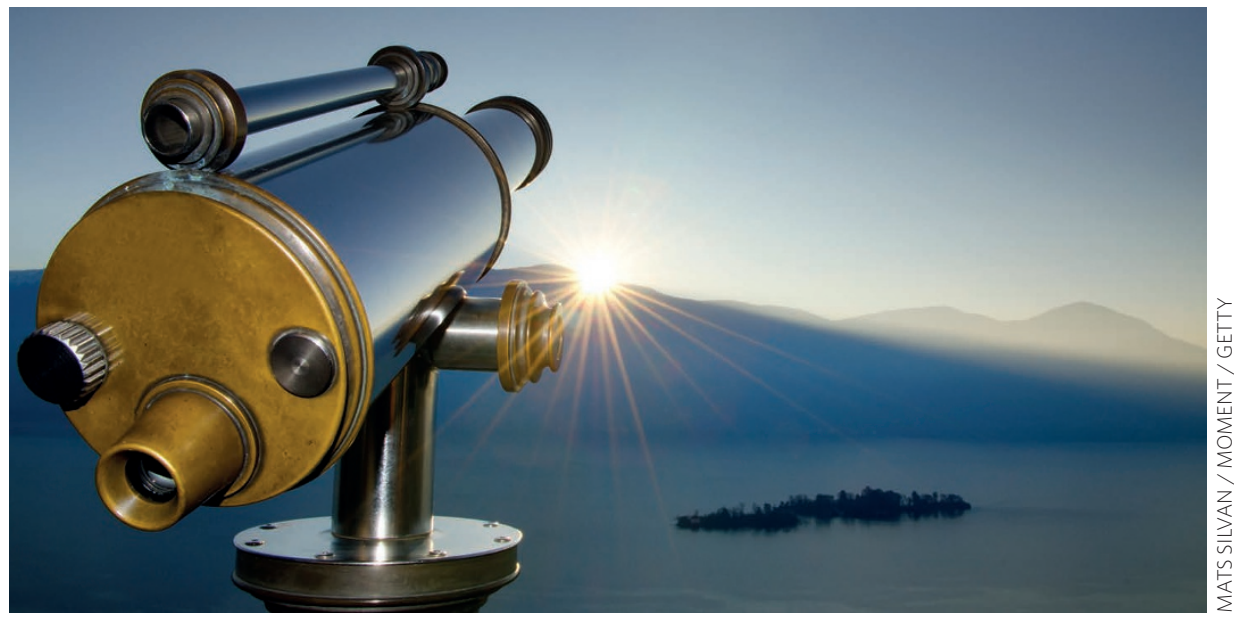

made by those Arab scholars, whose works were all translated into Latin.

Sometimes, however, the ebbs and flows of political events seem antagonistic to this basic need to pursue knowledge and seek beauty. There is a fear somehow that science may be a superfluous, even dangerous, activity: restrictions are put in place limiting international cooperation and exchange of ideas; discoveries by scientists of a different culture belittled. And even more worryingly, scientific findings that could directly impact the daily life of individuals or the destiny of entire populations are ignored. It is our duty as men and women of science to remind our politicians that only through more knowledge - not less - can we come up with effective solutions to the problems of the world. Understandably, this can be a tall order for a scientist, because it goes against the very reason why many of us chose to study science. We know science is a safe place, there is no room for irrationality and everything follows established rules (even though we don't know them most of the time). Unlike in politics, charlatans are easily exposed and cannot take advantage. But after all, it is this instinct to investigate, the delight that derives from it and the need to share knowledge that make us humans. We must work to bring to the fore what has united us for more than 200 thousand years, rather than focus on the differences that have emerged in the past few centuries.

Mercifully, scientists are not alone in this mission. A host of other endeavours are also so inherently human that have the power to unite peoples. Chief among them is art, a language that speaks to our senses and our minds, aiming too at making people reach a deeper level of engagement with the Universe. And sport; international competitions unite fans behind a common passion, athletes behind a common goal. Who can forget the pictures of the US and Iranian footballers arm in arm before their game at the 1998 FIFA World Cup; "We did more in 90 minutes than the politicians did in 20 years", one of the players is reported as saying. Or the selfie taken by two Korean gymnasts at the 2016 Olympic Games, one from the North and one from the South.

We should never assume the freedom to pursue knowledge is granted to us, as if we were living in a Garden of Eden. We must remain vigilant and reject complacency. The best way to do so is to take on board with us in our quest as many people as possible, conduce them by hand to see this 'admirable workmanship. How? Engage with political leaders, shape their agenda, advocate affordable education for all, give public lectures, collaborate with local and national newspapers, inspire pupils in public schools, get out there. We must fight this dangerous instinct to cocoon ourselves in the ivory tower. There is something more important than a corporate selfishness at stake here: defending our common identity.

Corrected after print: 13 March 2017 


\section{Correction}

In the Editorial 'Of knowledge and beauty'

(Nat. Nanotech. 12, 185; 2017) the quote from

Robert Boyle was misdated. The correct date is

1664. This was corrected after print in the online

versions of the Editorial on 13 March 2017. 